\title{
Toxicity of non-pyrethroid insecticides against Triatoma infestans (Hemiptera: Reduviidae)
}

\author{
Guillermo Carvajal, Gastón Mougabure-Cueto, Ariel Ceferino Toloza/ ${ }^{+}$ \\ Centro de Investigaciones de Plagas e Insecticidas, Instituto de Investigaciones Científicas y Técnicas para la Defensa, \\ Consejo Nacional de Investigaciones Científicas y Técnicas, Buenos Aires, Argentina
}

Triatoma infestans (Klug) is the main vector of Chagas disease, which is a public health concern in most Latin American countries. The prevention of Chagas disease is based on the chemical control of the vector using pyrethroid insecticides. In the last decade, different levels of deltamethrin resistance have been detected in certain areas of Argentina and Bolivia. Because of this, alternative non-pyrethroid insecticides from different chemical groups were evaluated against two T. infestans populations, NFS and El Malá, with the objective of finding new insecticides to control resistant insect populations. Toxicity to different insecticides was evaluated in a deltamethrin-susceptible and a deltamethrin-resistant population. Topical application of the insecticides fenitrothion and imidacloprid to first nymphs had lethal effects on both populations, producing $50 \%$ lethal dose ( $L D_{50}$ ) values that ranged from 5.2-28 $\mathrm{ng} /$ insect. However, amitraz, flubendiamide, ivermectin, indoxacarb and spinosad showed no insecticidal activity in first instars at the applied doses $\left(L D_{50}>200 \mathrm{ng}\right.$ /insect). Fenitrothion and imidacloprid were effective against both deltamethrin-susceptible and deltamethrin-resistant populations of $\mathrm{T}$. infestans. Therefore, they may be considered alternative non-pyrethroid insecticides for the control of Chagas disease.

Key words: Triatoma infestans - insecticide resistance - non-pyrethroid insecticides - imidacloprid - fenitrothion

In Argentina, the main vector of Trypanosoma cruzi, which causes Chagas disease, is Triatoma infestans (Klug, 1834) (Hemiptera: Reduviidae), a blood-sucking triatomine insect. Chagas disease is a public health concern in most Latin American countries. Currently, 1.5 million people are infected with this parasite in Argentina (MSN 2008) and over 90 million people are at risk of infection in Latin America (WHO 2006). The prevention of Chagas disease is based on the control of the insect vector, mainly using insecticides. Domestic infestations of T. infestans have been successfully controlled in much of the Southern Cone of South America by spraying infested dwellings with residual pyrethroid insecticides (Dias et al. 2002, Schofield et al. 2006). However, in the last decade, different levels of pyrethroid resistance have been detected in certain areas of Argentina and Bolivia (Picollo et al. 2005, Santo Orihuela et al. 2008, Toloza et al. 2008, Germano et al. 2010, Lardeux et al. 2010). This lack of effectiveness of deltamethrin for the field control of T. infestans is observed mainly in the Gran Chaco ecoregion, although there have been intensive vector control efforts in this area under the Southern Cone Initiative (Gürtler 2009).

The Gran Chaco ecoregion is a subarid region of 1.4 million $\mathrm{km}^{2}$ that extends over Argentina, Paraguay, Bolivia and Brazil. The human population in the area is low

Financial support: CONICET (PIP 112-200801-00198), WHO/TDR (ID A80360)

+Corresponding author: atoloza@conicet.gov.ar

Received 2 February 2011

Accepted 29 February 2012 (average $<5$ residents $/ \mathrm{km}^{2}$ ) and the vegetation consists of an open mosaic of hardwood forest, grasslands and savannas. Typical rural houses are built from mud and sticks and/or mud and thatch, providing a suitable habitat for the development of $T$. infestans populations.

In the Chaco province of Argentina, resistance to deltamethrin has recently been found in La Esperanza, a neighbouring locality of El Malá (G Mougabure-Cueto, unpublished observations). In another area of the Chaco province $103 \mathrm{~km}$ away from this area, a field reinfestation experiment was performed in the rural Pampa del Indio area after initially spraying the area with deltamethrin (JM Gurevitz, unpublished observations). The authors of this study observed a residual insect population after four initial pyrethroid sprayings that was successfully eliminated with the organophosphorous compound malathion.

With respect to the search for insecticides with alternative modes of action to control pyrethroid-resistant $T$. infestans populations, several options have been shown to be highly effective in controlling other pests. For example, imidacloprid has been found to be especially effective against a wide range of insect pests, such as the brown planthopper, Nilaparvata lugens (Wen et al. 2009), the sweet potato whitefly, Bemisia tabaci (Palumbo et al. 2001, Bi et al. 2002, Byrne et al. 2003) and the housefly, Musca domestica (Memmi 2010). In triatomines, the effect of non-pyrethroid insecticides was studied in the laboratory, with successful results being found for fipronil (Santo Orihuela et al. 2008, Toloza et al. 2008, Germano et al. 2010, Roca Acevedo et al. 2011), fenitrothion (Santo Orihuela et al. 2008, Toloza et al. 2008, Germano et al. 2010) and ivermectin (Dias et al. 2005).

In this study, we investigated a wide range of insecticides with different modes of action against $T$. infestans. 
The objective was to determine the toxicity of eight insecticides in two populations of T. infestans from deltamethrin-susceptible and deltamethrin-resistant areas.

\section{MATERIALS AND METHODS}

Insects - Samples from the El Malá field population of T. infestans were collected in November 2010 from infested houses in the Argentinean Chaco province (S25'56.077" W60'27.105") (Figure), where vector control using pyrethroid insecticides was considered ineffective by the authorities of the Chagas Program of Chaco province. Field-collected insects were transported to the Centro de Investigaciones de Plagas e Insecticides (CIPEIN) laboratory and further generations of these insects were bred in the laboratory. The first generation of these insects was used in the bioassays.

For comparison, we used a susceptible reference colony, NFS, derived from a domestic field population collected in December 2004 from Santiago del Estero, Argentina. This is an area where insects have been successfully controlled with deltamethrin. This population was maintained without any new external ingression of triatomines.

For rearing, each population was kept in enclosed boxes $(30 \times 30 \times 30 \mathrm{~cm})$ at $28 \pm 1^{\circ} \mathrm{C}, 50-60 \%$ relative humidity $(\mathrm{RH})$, with a photoperiod of 12:12 $\mathrm{h}(\mathrm{L}: \mathrm{D})$. A pigeon was provided weekly as a blood meal source (WHO 1994).

Chemicals - Selection of the insecticides to be tested was based on their non-pyrethroid mode of action, which may be a viable alternative to deltamethrin in resistant areas. Moreover, these insecticides have been shown to be effective against a wide variety of pests. The insecticides used in this study were technical grade samples of amitraz (99\%), deltamethrin (99\%), fenitrothion (98\%), flubendiamide $(99 \%)$, imidacloprid $(98 \%)$, indoxacarb $(99.5 \%)$, ivermectin (92\%) and spinosad (95\%). These chemicals were obtained from Dr Ehrenstorfer (Augsburg, Germany). Analytical grade acetone was purchased from JT Baker (San Pedro Xalostoc, state of Mexico, Mexico). Details of the site of action of each insecticide are shown in Table I.

Topical application bioassays - Resistance to deltamethrin in first instars is commonly associated with the resistance in the eggs of $T$. infestans populations in Argentina (Toloza et al. 2008). To detect resistance to deltamethrin in the El Malá population, nymphs and eggs were treated with the corresponding diagnostic dose (DD) estimated based on the susceptible reference colony. The best monitoring method for resistance detection is the use of a dose that accurately discriminates between resistant and susceptible genotypes. A dose that kills $>99.9 \%$ of the susceptible individuals $99 \%$ lethal dose $\left(\mathrm{LD}_{99}\right)$ or higher is significantly more efficient for detecting resistance than other techniques that tend to misclassify resistance (ffrench-Constant \& Roush 1990). In our analyses, the DD causes $100 \%$ mortality when used on the reference population and was established as $2 \times \mathrm{LD}_{99}$. The DDs for eggs and first instar nymphs were 20 and $2 \mathrm{ng} / \mathrm{insect}$, respectively.

Eggs - For toxicity analyses, eggs in late embryonic development stages (11-12 days) were selected using external morphological characteristics, as described previously (Picollo et al. 1979). The selected eggs were orange with dark eyespots. Groups of 10 eggs were fixed onto microscope slides with double-sided adhesive tape. The treatment of individual eggs was performed via topical application to the operculum of $0.2 \mu \mathrm{L}$ of deltamethrin diluted in acetone using a $10-\mu \mathrm{L}$ Hamilton syringe, according to the method reported by Picollo et al. (1976). Each batch of eggs received the DD of $0.1 \mathrm{mg} / \mathrm{mL}$ of deltamethrin (20 ng/egg) (Toloza et al. 2008). Controls received acetone. The total number of eggs used is given in Table II. Following topical application of the insecticide, the eggs were incubated in a rearing cabinet (FOC$225 \mathrm{E}$, Velp Scientifica, Milan, Italy) at $28 \pm 1^{\circ} \mathrm{C}, 50 \%$ $\mathrm{RH}$, with a photoperiod of 12:12 h (L:D). Mortality data were recorded 10 days after treatment to determine the

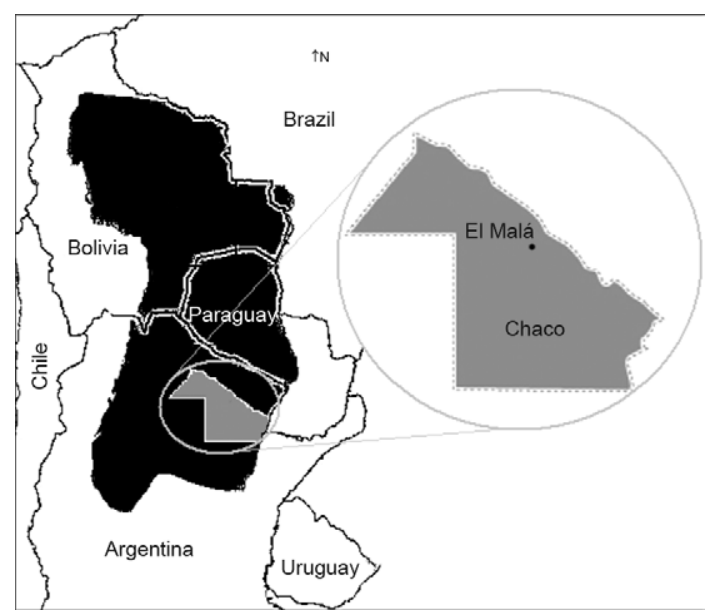

Map where El Malá field population was obtained in the Chaco province, Argentina.

TABLE I

Mode of action and chemical group of the insecticides used

\begin{tabular}{|c|c|c|}
\hline Insecticide & Chemical group & Mode of action \\
\hline Deltamethrin & Pyrethroids & $\begin{array}{l}\text { Sodium } \\
\text { channel modulator }\end{array}$ \\
\hline Amitraz & Amitraz & $\begin{array}{l}\text { Octopamine } \\
\text { receptor agonist }\end{array}$ \\
\hline Fenitrothion & Organophosphates & $\begin{array}{l}\text { Acetylcholinesterase } \\
\text { inhibitor }\end{array}$ \\
\hline Flubendiamide & Diamides & $\begin{array}{l}\text { Ryanodine } \\
\text { receptor modulator }\end{array}$ \\
\hline Imidacloprid & Neonicotinoids & $\begin{array}{l}\text { Nicotinic acetylcholine } \\
\text { receptor agonist }\end{array}$ \\
\hline Indoxacarb & Indoxacarb & $\begin{array}{l}\text { Voltage-dependent } \\
\text { sodium channel blocker }\end{array}$ \\
\hline Ivermectin & Macrocyclic lactone & $\begin{array}{c}\text { Chloride } \\
\text { channel activator }\end{array}$ \\
\hline Spinosad & Spinosyns & $\begin{array}{l}\text { Nicotinc acetylcholine } \\
\text { receptor allosteric activator }\end{array}$ \\
\hline
\end{tabular}


number of eggs that failed to hatch. This period was also used to check whether any delayed hatching occurred in the control (Toloza et al. 2008).

First instars - T. infestans first instars (5-7 days old) that had been starved since eclosion were selected for toxicity tests according to the World Health Organization protocol(WHO 1994). The bioassays consisted of the topical application of $0.2 \mu \mathrm{L}$ of the insecticide diluted in acetone on the dorsal abdomen of the first instar using a $10-\mu \mathrm{L}$ Hamilton syringe equipped with an automatic dispenser. The control groups received only pure acetone. The final concentrations tested ranged from $0.01-1 \mathrm{mg} /$ $\mathrm{mL}$ for deltamethrin, $0.5-5 \mathrm{mg} / \mathrm{mL}$ for flubendiamide, $0.01-1 \mathrm{mg} / \mathrm{mL}$ for fenitrothion, $0.5-5 \mathrm{mg} / \mathrm{mL}$ for amitraz,

\section{TABLE II}

Response of Triatoma infestans eggs and first instars to deltamethrin diagnostic dose

\begin{tabular}{|c|c|c|c|c|}
\hline \multirow[b]{2}{*}{ Population } & \multicolumn{2}{|r|}{ Eggs } & \multicolumn{2}{|r|}{ First instars } \\
\hline & $\mathrm{n}$ & $\begin{array}{c}\text { Mortality with } \\
\text { diagnostic dose (\%) } \\
\text { (20 ng/insect) }\end{array}$ & $\mathrm{n}$ & $\begin{array}{c}\text { Mortality with } \\
\text { diagnostic dose (\%) } \\
\text { (2 ng/insect) }\end{array}$ \\
\hline NFS & 70 & 100 & $120^{a}$ & 100 \\
\hline El Malá & 90 & 0 & 90 & 0 \\
\hline
\end{tabular}

$a$ : data from Roca Acevedo et al. (2011).

TABLE III

Toxicity of insecticides against Triatoma infestans first instars from Argentina

\begin{tabular}{lcccc}
\hline Insecticide & Population & $\mathrm{n}$ & Slope $\pm \mathrm{SE}$ & $\begin{array}{c}\mathrm{LD}_{50} \mathrm{ng} / \mathrm{insect} \\
(95 \% \mathrm{CI})\end{array}$ \\
\hline Deltamethrin & $\mathrm{NFS}^{a}$ & 120 & $3.10 \pm 0.26$ & $0.13(0.11-0.15)$ \\
& El Malá $^{*}$ & 90 & $1.0 \pm 0.4$ & $134(100-182)$ \\
Amitraz & NFS & 30 & - & $>200$ \\
Fenitrothion & El Malá & 30 & - & $>200$ \\
Flubendiamide & NFS & 80 & $2.07 \pm 0.19$ & $10.8(4.0-26.6)$ \\
& El Malá & 136 & $1.90 \pm 0.32$ & $28.0(18.2-43.2)$ \\
Imidacloprid & El Malá & 30 & - & $>200$ \\
& NFS & 95 & $2.47 \pm 0.21$ & $5.2(3.4-7.8)$ \\
Indoxacarb & El Malá & 174 & $1.72 \pm 0.17$ & $9.2(7.4-11.2)$ \\
& NFS & 30 & - & $>200$ \\
Ivermectin & El Malá & 30 & - & $>200$ \\
& NFS & 30 & - & $>200$ \\
Spinosad & El Malá & 30 & - & $>200$ \\
& NFS & 30 & - & $>200$ \\
& El Malá & 30 & - & $>200$ \\
\hline
\end{tabular}

$a$ : data from Roca Acevedo et al. (2011); CI: confidence interval; LD: lethal dose; SE: standard error.
$0.5-5 \mathrm{mg} / \mathrm{mL}$ for indoxacarb, $0.5-5 \mathrm{mg} / \mathrm{mL}$ for spinosad, $0.01-5 \mathrm{mg} / \mathrm{mL}$ for ivermectin and from $0.0025-0.5 \mathrm{mg} /$ $\mathrm{mL}$ for imidacloprid. All concentrations were replicated at least three times with a minimum of 10 insects per replicate. To calculate the LD values at a $\mathrm{p}<0.05$, a minimum of 30 insects per concentration is required and between $10-90 \%$ mortality should be observed (Robertson et al. 2007). All treatments were performed on different days. Mortality was evaluated after $24 \mathrm{~h}$ by placing the insects on a circular piece of filter paper $(11 \mathrm{~cm}$ diameter) and observing their ability to walk. Only nymphs that were able to walk from the centre of the filter paper to the border were considered alive. The total number of insects used is shown in Table III.

Statistical analysis - Mortality data were analysed using POLO Plus software v.2.0. Dose-mortality data were subject to a probit analysis (Litchfield \& Wilcoxon 1994) to estimate the LD (ng/insect) required to kill 50\% of treated the individuals $\left(\mathrm{LD}_{50}\right)$. The resistance ratio (RR) was calculated as described by Robertson et al. (2007) through comparison with the susceptible reference population, NFS.

\section{RESULTS}

Comparative susceptibility to deltamethrin of eggs and first instars from T. infestans populations - The susceptibility of eggs from a field population, El Malá, was evaluated and compared with the field reference strain, NFS. At a DD of $20 \mathrm{ng} / \mathrm{insect}, 100 \%$ mortality of NFS eggs was observed, whereas all El Malá eggs hatched ( $0 \%$ mortality) (Table II). With regard to the first instars, treatment with a DD of $2 \mathrm{ng} /$ insect had no lethal effect on the El Malá population ( $0 \%$ ), but resulted in a mortality of $100 \%$ in the NFS population. The $\mathrm{LD}_{50}$ values for the NFS and El Malá populations were 0.13 and 134 ng/insect, respectively. Moreover, El Malá individuals showed a high $\mathrm{RR}_{50}$ of 1.031 , with $95 \%$ confidence interval of 909.1 and 1.213.3. The estimates of the $\mathrm{LD}_{95}$ and $\mathrm{RR}_{95}$ values for the resistant El Malá population were $1.336 .0 \mathrm{ng} /$ insect and 3.036.4, respectively.

Toxicity to insecticides with different modes of action in T. infestans first instars from Argentina - Toxicity to different insecticides was evaluated in the NFS and El Malá populations. The susceptibility values $\left(\mathrm{LD}_{50}\right.$ values) are shown in Table III. The insecticides amitraz, flubendiamide, ivermectin, indoxacarb and spinosad were not toxic to the first instars at the applied doses $\left(\mathrm{LD}_{50}>200\right.$ $\mathrm{ng} /$ insect). In contrast, fenitrothion and imidacloprid were lethal, with $\mathrm{LD}_{50}$ values that ranged from 5.2-28 ng/insect. Moreover, the calculated $\mathrm{LD}_{50}$ values were not significantly different between the NFS and El Malá populations.

\section{DISCUSSION}

Chagas disease occurs throughout Latin America; however, the manifestations and epidemiological characteristics of the disease vary among epidemic areas, mainly due to differences in social and economic development (WHO 2002).

The experimental results of the present study demonstrated high resistance to deltamethrin associated with ineffective field treatment of T. infestans in El Malá, 
which is located in the Chaco province of Argentina. These results are in accordance with those of previous studies performed in the Gran Chaco ecoregion, where resistance to deltamethrin was also found in both domestic and peridomestic T. infestans populations from Argentina and Bolivia (Picollo et al. 2005, Santo Orihuela et al. 2008, Toloza et al. 2008, Germano et al. 2010, Lardeux et al. 2010). Therefore, it is necessary to find insecticides with alternative modes of action to that of pyrethroid chemicals to control this vector.

This is the first study to demonstrate the efficacy of seven insecticides with an alternative mode of action to deltamethrin against $T$. infestans under laboratory conditions.

The insecticides amitraz, flubendiamide, indoxacarb, ivermectin and spinosad showed no lethality at doses of 1 and $5 \mathrm{mg} / \mathrm{mL}$. Higher doses were not evaluated because of methodological problems caused by the availability of the insecticides. However, these results are important because these insecticides have never been studied in T. infestans previously; therefore, they contribute to the toxicological profile of these insecticides and provide a foundation for futures studies. A possible explanation for the observed lack of effectiveness may be related to a problem regarding the penetration of the insecticides. This type of problem has been reported for the organochlorine DDT when used against T. infestans (Fontán \& Zerba 1992). The authors of this previous study found that the penetration rate of DDT was related to the nutritional state of the nymphs, with insects that were fed on pigeons $(1.09 \mu \mathrm{g} /$ insect) being more susceptible to DDT than those that were starved ( $>150 \mu \mathrm{g} /$ insect). This remarkable difference was due to the cuticular distention associated with blood ingestion, which allows higher penetration of the insecticide through the intersegmental membrane of the cuticle (Bennet-Clark 1962).

In contrast, the $\mathrm{LD}_{50}$ values obtained for fenitrothion and imidacloprid were similar to the $\mathrm{LD}_{50}$ values found for the organophosphorous compound malathion, which has been proven to be effective against pyrethroid-resistant $T$. infestans field populations (JM Gurevitz, unpublished observations).

Twenty years after the implementation of a strategy aimed to eliminate Chagas disease through the interruption of vectorial transmission and the screening of blood donors, the Southern Cone Initiative has reduced the incidence of Chagas disease by an average of $94 \%$ in the countries of Argentina, Brazil, Bolivia, Chile, Paraguay and Uruguay (WHO 2002). However, in the Gran Chaco ecoregion, $T$. infestans numbers have not been reduced and this area is considered to represent the last main barrier to be conquered (Gürtler 2009). The lack of efficacy in this area may be attributable to several factors, such as incomplete insecticide coverage and entomological surveillance, interruption of local control programs due to economic problems and harsh environmental working conditions, such as temperatures ranging from $-10-50^{\circ} \mathrm{C}$ and the increasing desertification of some areas (Porcasi et al. 2006, Gürtler 2009, Vazquez-Prokopec et al. 2009). As noted by Gürtler et al. (2004), peridomestic populations of T. infestans in the Gran Chaco ecoregion may exhibit a high rate of survival after chemical control actions, leading to a low efficacy of these treatments. These conditions are not mutually exclusive, but the adaptation of this species to this ecoregion should also be considered. Moreover, domestic T. infestans populations from Bolivia and Argentina have been found to exhibit different toxicological and biochemical profiles affecting their susceptibility to insecticides (Santo Orihuela et al. 2008, Toloza et al. 2008, Germano et al. 2010). Recently, Roca Acevedo et al. (2011) studied the susceptibility of several wild populations of $T$. infestans from Bolivia to insecticides. Although the authors found differences in the toxicological responses of first instars to deltamethrin, their enzymatic activities were similar. Because these populations were collected from a sylvatic habitat, no chemical control interventions were performed. Thus, wild $T$. infestans from different geographic areas of Bolivia possess different toxicological profiles or phenotypes.

The only insecticide formulations approved for use in the field control of $T$. infestans are those containing the pyrethroid deltamethrin and the organophosphates fenitrothion and malathion. However, Rojas de Arias and Fournet (2002) showed that the phenylpyrazole fipronil, a GABA-gated chloride channel antagonist, exhibited up to three months of residual efficacy on mud and lime-coated mud blocks when applied at a concentration of $200 \mathrm{mg}$ a.c $/ \mathrm{m}^{2}$, resulting in mortality rates of approximately $50 \%$ in triatomines. This finding indicated the potential of this non-pyrethroid insecticide in the control of Chagas disease vectors. In our assays, imidacloprid was effective against deltamethrin-resistant $T$. infestans under laboratory conditions. A field study should also be performed to study the residual effect of this insecticide on different surfaces. Finally, it is essential that other insecticidal compounds, especially those with alternative modes of action to pyrethroids and organophosphates, are rapidly made available for T. infestans control programs in South America.

\section{ACKNOWLEDGEMENTS}

To Jorge Nazir, Cynthia Spillman and all the people of the Chaco Chagas Program, for their help in collecting T. infestans in the field, and to anonymous reviewers, for extremely helpful comments.

\section{REFERENCES}

Bennet-Clark HC 1962. Active control of the mechanical properties of insect endocuticle. J Insect Physiol 8: 627-633.

Bi JL, Toscano NC, Ballmer GR 2002. Greenhouse and field evaluation of six novel insecticides against the greenhouse whitefly Trialeurodes vaporariorum onstrawberries. Crop Prot 21: 49-55.

Byrne FJ, Castle S, Prabhaker N, Toscano NC 2003. Biochemical study of resistance to imidacloprid in B biotype Bemisia tabaci from Guatemala. Pest Manag Sci 59: 347-352.

Dias JCP, Silveira AC, Schofield CJ 2002. The impact of Chagas disease control in Latin America: A Review. Mem Inst Oswaldo Cruz 97: 603-612.

Dias JCP, Schofield CJ, Machado EMM, Fernandes AJ 2005. Ticks, ivermectin and experimental Chagas disease. Mem Inst Oswaldo Cruz 100: 829-832.

ffrench-Constant R, Roush R 1990. Resistance detection and documentation: the relative roles of pesticidal and biochemical assays. 
In R Roush, B Tabashnik, Pesticide resistance in arthropods, Chapman and Hall, New York, p. 4-38.

Fontán A, Zerba E 1992. Influence of the nutritional state of over the insecticidal activity of DDT. Comp. Biochem Physiol 101: 589-591.

Germano MD, Roca Acevedo G, Mougabure Cueto GA, Toloza AC, Vassena CV, Picollo MI 2010. New findings of insecticide resistance in Triatoma infestans (Heteroptera: Reduviidae) from the Gran Chaco. J Med Entomol 47: 1077-1081.

Gürtler RE 2009. Sustainability of vector control strategies in the Gran Chaco region: current challenges and possible approaches. Mem Inst Oswaldo Cruz 104 (Suppl. I): 52-59.

Gürtler RE, Canale DM, Spillman C, Stariolo R, Salomón OD, Blanco S, Segura EL 2004. Effectiveness of residual spraying with deltamethrin and permethrin on peridomestic populations of Triatoma infestans in rural western Argentina: a district-wide randomized trial. Bull World Health Organ 82: 196-205.

Lardeux F, Depickère S, Duchon S, Chavez T 2010. Insecticide resistance of T. infestans (Hemiptera: Reduviidae) vector of Chagas disease in Bolivia. Trop Med Int Health 15: 1037-1048.

Litchfield J, Wilcoxon F 1994. A simplified method of evaluating dose-effect experiments. J Pharmacol Exp Ther 96: 99-113.

Memmi BK 2010. Mortality and knockdown effects of imidacloprid and methomyl in house fly (Musca domestica L., Diptera: Muscidae) populations. J Vector Ecol 35: 144-148.

MSN - Ministerio de Salud de la Nación 2008. Programa Federal de Chagas. Guía básica para el control vectorial, MSN, Buenos Aires, 13 pp.

Palumbo JC, Horowitz AR, Prabhaker N 2001. Insecticidal control and resistance management for Bemisia tabaci. Crop Prot 20: 739-765.

Picollo de Villar MI, Zerba E, Wood E, Licastro S 1979. Neurogenesis and occurrence of cholinesterase in eggs of Triatoma infestans. Comp Biochem Physiol 65: 65-70.

Picollo M, Wood E, Licastro S, Zerba E 1976. Acción ovicida de insecticidas organofosforados en Triatoma infestans (vinchuca). Acta Bioquim Clin Latinoam 10: 309-319.

Picollo MI, Vassena CV, Santo Orihuela P, Barrios S, Zerba EN 2005. High resistance to pyrethroid insecticides associated with ineffective field treatments in Triatoma infestans (Hemiptera: Reduviidae) from northern Argentina. J Med Entomol 42: 637-642.
Porcasi X, Catala SS, Hrellac H, Scavuzzo MC, Gorla DE 2006. Infestation of rural houses by Triatoma infestans (Hemiptera: Reduviidae) in southern area of Gran Chaco in Argentina. $J$ Med Entomol 43: 1060-1067.

Robertson JL, Russell RM, Preisler HK, Savin NE 2007. Bioassays with arthropods, 2nd ed., CRC, Boca Raton, 199 pp.

Roca Acevedo G, Mougabure Cueto G, Germano M, Santo Orihuela P, Rojas Cortez M, Noireau F, Picollo MI, Vassena CV 2011. Susceptibility of sylvatic Triatoma infestans from andeans valleys of Bolivia to deltamethrin and fipronil. J Med Entomol 48: 828-835.

Rojas de Arias A, Fournet A 2002. Fipronil insecticide: novel application against Triatomine insect vectors of Chagas disease. Mem Inst Oswaldo Cruz 97: 535-539.

Santo Orihuela PL, Vassena CV, Zerba EN, Picollo MI 2008. Relative contribution of monooxygenase and esterase to pyrethroid resistance in Triatoma infestans (Hemiptera: Reduviidae) from Argentina and Bolivia. J Med Entomol 45: 298-306.

Schofield CJ, Jannin J, Salvatella R 2006. The future of Chagas disease control. Trends Parasitol 12: 583-588.

Toloza AC, Germano M, Mougabure Cueto G, Vassena CV, Zerba E, Picollo MI 2008. Differential patterns of insecticide resistance in eggs and first instars of Triatoma infestans (Hemiptera: Reduviidae) from Argentina and Bolivia. J Med Entomol 45: 421-426.

Vazquez-Prokopec GM, Spillman C, Zaidenberg M, Kitron U, Gürtler RE 2009. Cost-effectiveness of vector control strategies against Triatoma infestans in rural northwestern Argentina. PLoS Negl Trop Dis 3: e363.

Wen Y, Liu Z, Bao H, Han Z 2009. Imidacloprid resistance and its mechanisms in field populations of brown planthopper, Nilaparvata lugens Stål in China. Pest Biochem Physiol 94: 36-42.

WHO - World Health Organization 1994. Protocolo de evaluación de efecto insecticida sobre triatominos. Acta Toxicol Argent 2: 29-32.

WHO - World Health Organization 2002. Control of Chagas disease. Tech Rep Ser 905: 82-83.

WHO - World Health Organization 2006. Pesticides and their application for the control of vectors and pests of public health importance, 6th ed., WHO, Geneva, p. 64-66. 